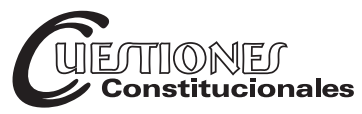

Revista Mexicana de Derecho Constitucional Núm. 41, julio-diciembre 2019

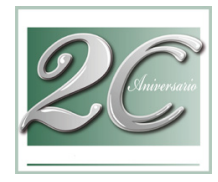

\title{
Los sujetos vulnerables en la jurisprudencia "transformadora" de la Corte Interamericana de Derechos Humanos
}

\author{
The Vulnerable Subjects in the "Transformative" \\ Jurisprudence of the Inter-American \\ Court of Human Rights
}

Sergio GARCÍA RAMÍREZ*

RESUMEN: La Corte Interamericana de Derechos Humanos ha producido una nutrida y relevante jurisprudencia en el curso de cuatro décadas, a partir del establecimiento de ese tribunal regional en 1979, año en que entró en vigor la Convención Americana sobre Derechos Humanos. Esa jurisprudencia consta de un importante número de sentencias, opiniones consultivas y resoluciones sobre medidas provisionales y cumplimiento de sentencias. En este artículo se ofrece un panorama de uno de los sectores más incisivos y trascendentes de la jurisprudencia interamericana, que concierne a los derechos y la situación jurídica de personas consideradas "vulnerables", en virtud de la situación de debilidad, desvalimiento o marginación en que se encuentran. El contingente de los "vulnerables" constituye una parte sustancial de la población en los Estados sobre los que ejerce jurisdicción la Corte Interamericana. El autor pasa revista a los criterios adoptados por dicho tribunal acerca de diversas categorías de sujetos vulnerables, a los que se refieren varios instrumentos internacionales de alcance universal o regional. Al respecto, son muy significativas las Cien Reglas de Brasilia sobre el Acceso a la Justicia de personas en esa condición, y el Protocolo de
ABSTRACT: Since its establishment in 1979, the year in which the American Convention on Human Rights entered into force, the InterAmerican Court of Human Rights has produced a rich and noteworthy case law over the course of four decades. This case law comprises a significant number of judgments, advisory opinions and decisions on provisional measures and the enforcement of judgments. This article provides an overview of one of the most decisive and transcendent sectors of inter-American case law, which pertains to the rights and legal status of persons considered "vulnerable" on account of the situation of weakness, helplessness or marginalization in which they find themselves. The "vulnerable" group constitutes a substantial part of the population in the States under the jurisdiction of the Inter-American Court. The author reviews the criteria adopted by the Court regarding various categories of vulnerable persons, referred to in various international instruments of universal or regional scope. In this sense, the Brasilia Regulations Regarding Access to Justice for Vulnerable People and the Santiago Protocol adopted by the IberoAmerican Judicial Summit are very significant. The categories considered in this article are:

\footnotetext{
* Investigador en el Instituto de Investigaciones Jurídicas de la UNAM, México.
} 
Esta revista forma parte del acervo de la Biblioteca Jurídica Virtual del Instituto de Investigaciones Jurídicas de la UNAM

Santiago adoptado por la Cumbre Iberoamericana de Tribunales. Las categorías que considera este artículo son: mujeres, niños y niñas, indígenas, afrodescendientes, personas con discapacidad, migrantes, desplazados y personas privadas de libertad, a los que últimamente se añaden otros grupos que han merecido la atención del Tribunal: periodistas, defensores de derechos humanos e integrantes de la comunidad LGBTTI. La jurisprudencia interamericana sobre vulnerables ha influido en la recepción nacional del derecho internacional de los derechos humanos en este ámbito geopolítico.

Palabras clave: Corte Interamericana, jurisprudencia, sentencias, opiniones consultivas, vulnerables, mujeres, niños, indígenas, afrodescendientes, discapacidad, migrantes, desplazados, personas privadas de libertad, periodistas, defensores de derechos, LGBTTI. women, children, indigenous people, people of African descent, people with disabilities, migrants, displaced people and people deprived of their liberty. To this list, other groups that have drawn the attention of the Court have recently been added: journalists, human rights defenders and members of the LGBTTI community. Inter-American case law on vulnerable persons has influenced the national incorporation of international human rights law in this geopolitical sphere.

Keywords: Inter-American Court, Case law, Judgments, Advisory opinions, Vulnerable persons, Women, Children, Indigenous peoples, People of African descent, Persons with disabilities, Migrants, Displaced persons, Persons deprived of their liberty, Journalists, Human Rights activists, LGBTTI.

SUMARIO: I. Preámbulo. II. Introducción. III. Mujeres. IV. Niñas, niños y adolescentes. V. Indígenas. VI. Personas con discapacidad. VII. Migrantes. VIII. Personas en situación de pobreza. IX. Privados de la libertad. X. Periodistas. XI. Defensores de derechos humanos. XII. LGBTI.

\section{PREÁmbulo}

Desde la fecha de vigencia de la Convención Americana sobre Derechos Humanos $(\mathrm{CADH})^{1}$ y del establecimiento de la Corte Interamericana (Corte o Corte IDH), ${ }^{2}$ ésta ha formado una jurisprudencia valiosa que ha influido en el ordenamiento y las prácticas de los Estados parte de ese tratado internacional. La propia Corte se ha ocupado en difundir amplia-

1 La Convención fue adoptada el 22 de noviembre de 1969 en San José, Costa Rica. En los términos del artículo 72.4, entró en vigor el 18 de julio de 1978 al contar con la adhesión o ratificación de once Estados.

2 La Corte Interamericana de Derechos Humanos fue establecida el 22 de mayo de 1979. Cfr. varios autores, Corte Interamericana de Derechos Humanos. Memoria de la instalación, 2a. ed., San José, Unión Europea, 1999, pp. 9 y 10. 
mente su jurisprudencia, además de las obras publicadas con el mismo designio. $^{3}$

En esa jurisprudencia, que abarca los pronunciamientos emitidos a través de opiniones consultivas, sentencias en casos contenciosos, medidas provisionales y otras resoluciones, resulta particularmente relevante el tratamiento de temas relativos a sujetos "vulnerables". A mi juicio, esta atención destacada integra - junto a las decisiones acerca de las consecuencias jurídicas de hechos ilícitos (reparaciones) - un tema sobresaliente en la doctrina jurisprudencial del tribunal de San José.

En otras ocasiones he analizado la jurisprudencia interamericana en torno a sujetos o grupos vulnerables, en general; para ello he presentado un panorama que comprende a diversas categorías de vulnerables examinadas por la Corte IDH. ${ }^{4}$ En este artículo retomo esa materia, a partir de algunos pronunciamientos básicos del tribunal y, sobre todo, de las decisiones adoptadas en fechas recientes. No invoco aquí, por lo tanto, todas las resoluciones a propósito de estos temas. Quien desee conocer y analizar con detalle el conjunto de la jurisprudencia en cada una de las hipótesis que abarca este trabajo, puede hacerlo mediante la consulta directa de las opiniones y sentencias que figuran en el presente artículo, que suelen mencionar los precedentes. Por lo que toca a mis propias reflexiones en torno a estos temas, las referencias pertinentes figuran en los apartados sobre las diversas categorías de sujetos vulnerables.

Debo mencionar que en el breve panorama que ahora presento - en cuya elaboración ha participado Irving Rodríguez, becario en el Instituto de Investigaciones Jurídicas de la UNAM, a quien agradezco su colaboración- me referiré a algunas categorías o grupos que no aparecieron en

3 La Corte ha difundido su jurisprudencia y publicaciones en su sitio web: http:// www.corteidh.or.cr.

Cfr., asimismo, García Ramírez, Sergio, Los derechos humanos y la jurisdicción interamericana, México, Porrúa, 2018, y Panorama de la jurisprudencia interamericana de derechos humanos, México, CNDH —en prensa-; Salmón, Elizabeth, Jurisprudencia de la Corte Interamericana de Derechos Humanos, Bogotá, Editorial Universidad del Rosario, 2011, y Ferrer Mac-Gregor Poisot, Eduardo et al. (coords.), Derechos humanos en la Constitución: comentarios de la jurisprudencia constitucional e interamericana, México, SCJN-Fundación Konrad Adenauer-UNAM, Instituto de Investigaciones Jurídicas, 2013, ts. I-II.

4 Cfr. García Ramírez, Sergio, "Los «vulnerables» ante la jurisdicción interamericana de los derechos humanos", Revista Brasileira de Ciências Criminais, núm. 105, 2013, pp. 225-246, y La Corte Interamericana de Derechos Humanos, 2a. ed., México, PorrúaUNAM, 2015, pp. 657-673. 
anteriores trabajos de mi autoría. Éstos aludieron a la jurisprudencia sobre mujeres, niños, indígenas, personas que tienen alguna forma de discapacidad, migrantes y sujetos privados de la libertad. En este artículo incluyo igualmente la referencia a otros sectores que deben ser considerados bajo el rubro de la jurisprudencia sobre grupos o sujetos vulnerables, que la Corte ha estudiado y que han motivado decisiones de notable importancia y trascendencia, a saber: integrantes del conjunto identificado con las siglas LGBTI, periodistas y defensores de derechos humanos. Actualmente $-\mathrm{y}$ desde hace tiempo- , todos ellos ofrecen las características de vulnerabilidad que determinan su inclusión en este examen jurisprudencial.

\section{INTRODUCCIÓN}

Parece ilusorio - y seguramente lo es - proclamar el imperio de los derechos humanos y aguardar su efectiva práctica universal cuando un amplio sector de la población — sector mayoritario, inclusive - se halla en condiciones de desventaja que impiden o al menos obstruyen el acceso a derechos y garantías. Me refiero al universo de los vulnerables, ${ }^{5}$ sea por motivos individuales, sea por pertenencia a grupos menos poderosos o francamente desvalidos.

5 Conforme a las Reglas de Brasilia, la expresión "personas en situación de vulnerabilidad" comprende a quienes "por razón de su edad, género, estado físico o mental, o por circunstancias sociales, económicas, étnicas y/o cultura, encuentran especiales dificultades para ejercitar con plenitud ante el sistema de justicia los derechos reconocidos por el ordenamiento jurídico". Reglas de Brasilia sobre Acceso a la Justicia de las Personas en Condición de Vulnerabilidad, aprobadas en la XIV Cumbre Judicial Iberoamericana, 2008, Brasilia, sección 2a. 1.

La "situación de vulnerabilidad" no debe entenderse como una condición de ser, sino de estar, "ya (que) no es la característica natural de la vida misma, sino las consecuencias de determinada organización jurídica, política y social que hace vulnerables a ciertos grupos sociales por encontrarse en determinadas circunstancias o por poseer determinados caracteres identitarios, provocándoles un daño, lesión o discriminación, que no son vulnerables sino que están vulnerables". Ribotta, Silvina, "Reglas de Brasilia sobre Acceso a la Justicia de la Personas en Condición de Vulnerabilidad. Vulnerabilidad, pobreza y acceso a la justicia", Revista Electrónica Iberoamericana, vol. 6, núm. 2, 2012, p. 8, disponible en: https://www.urjc.es/images/ceib/revista_electronica/vol_6_2012_2/ REIB_06_02_04Ribotta.pdf.

En la misma línea, cfr. González Le Saux, Marianne y Parra Vera, Óscar, "Concepciones y cláusulas de igualdad en la jurisprudencia de la Corte Interamericana. A propósito del caso Apitz", Revista IIDH, vol. 47, p. 132. 
El esfuerzo por generar condiciones de ejercicio razonable de los derechos humanos de aquellos titulares se manifiesta por múltiples vías que se hallan en curso. Entre éstas figuran las denominadas "leyes del más débil", ${ }^{6}$ a las que debe acompañar, en una vertiente aplicativa de suma relevancia, lo que podríamos denominar "jurisprudencia de los más débiles", esto es, criterios jurisprudenciales - nacionales e internacionales - que generen condiciones de acceso a los derechos a favor de los vulnerables. A esto me he referido en varias ocasiones. ${ }^{7}$ En la obra de la Corte esa jurisprudencia posee un lugar prominente. Constituye, en rigor, un dato característico de la jurisprudencia interamericana sobre derechos humanos.

En el plano continental existe una fuerte tendencia en aquella dirección, que se muestra en diversas aportaciones de las cumbres judiciales, emisoras de documentos relevantes que concurren a sustentar la jurisprudencia de la región. ${ }^{8}$ En el orden doméstico, los tribunales han producido orientaciones, lineamientos y disposiciones que marchan en el mismo sentido; así, por ejemplo, en el caso de México. ${ }^{9}$

En el orden público internacional campea el principio de igualdad ${ }^{10}$ arraigado en el jus cogens,${ }^{11}$ del que la Corte Interamericana de Derechos

6 Cfr. Ferrajoli, Luigi, Derechos y garantías: la ley del más débil, trad. de Andrea Greppi, Madrid, Trotta, 2009, pp. 15 y ss.

7 Cfr. García Ramírez, Los derechos humanos..., cit., pp. 242-253.

8 Reglas de Brasilia sobre Acceso a la Justicia..., cit.; Protocolo Iberoamericano de Actuación Judicial para Mejorar el Acceso a la Justicia de Personas con Discapacidad, Migrantes, Niñas, Niños, Adolescentes, Comunidades y Pueblos Indígenas, Santiago, 2014, y Protocolo de Actuación Judicial para Casos de Violencia de Género contra las Mujeres, Santiago, 2014.

9 Suprema Corte de Justicia de la Nación (SCJN), Protocolo de actuación para quienes imparten justicia en casos que involucren derechos de personas, comunidades y pueblos indigenas, 2a. ed., México, SCJN, 2014; Protocolo de actuación para quienes imparten justicia en casos que involucren niñas, niños y adolescentes, México, 2a. ed., SCJN, 2014; Protocolo de actuación para quienes imparten justicia en casos relacionados con proyectos de desarrollo e infraestructura, México, SCJN, 2014; Protocolo de actuación para quienes imparten justicia en casos que involucren a personas migrantes y sujetas de protección internacional, 2a. ed., México, SCJN, 2015; Protocolo de actuación para quienes imparten justicia en casos que involucren la orientación sexual o la identidad de género, 2a. ed., México, SCJN, 2015; Protocolo de actuación para quienes imparten justicia en casos que involucren derechos de personas con discapacidad, 2 a. ed., México, SCJN, 2014, y Protocolo para juzgar con perspectiva de género. Haciendo realidad el derecho a la igualdad, 2a. ed., México, SCJN, 2015.

10 Cfr. OC-4/84, 19 de enero de 1984, párr. 55; Espinoza Gonzáles, 20 de noviembre de 2014, párr. 216, y Duque, 26 de febrero de 2016, párr. 91. 
Humanos se ha ocupado ampliamente. ${ }^{12}$ Se trata de un postulado de importancia decisiva para la universalidad de los derechos fundamentales y las garantías que lo amparan. Por este medio se reconoce la unidad de dignidad de quienes integramos el género humano, ${ }^{13}$ de la que deriva la admisión incuestionada de derechos y libertades a favor de todas las personas.

Empero, existen factores de hecho - y también, en su hora y circunstancia, de derecho - que plantean obstáculos de mayor o menor entidad para el verdadero disfrute de esos derechos. Ello obliga a establecer, a título de matiz o complemento del principio de igualdad -o factor para el efectivo imperio de éste- , un principio de signo característico: principio de "especificidad", ${ }^{14}$ que opera como factor de igualación de los titulares de derechos, naturalmente desiguales, a través de distintos medios acogidos por el orden nacional e internaciona ${ }^{15}$ en calidad de protecciones especiales ${ }^{6}$

11 El artículo 53 de la Convención de Viena sobre el Derecho de los Tratados señala que el jus cogens "es una norma aceptada y reconocida por la comunidad internacional de Estados en su conjunto como norma que no admite acuerdo en contrario y que sólo puede ser modificada por una norma ulterior de derecho internacional general que tenga el mismo carácter”. Sobre este tema, cfr. Gómez Robledo, Antonio, El ius cogens internacional. Estudio histórico-crítico, México, UNAM, Instituto de Investigaciones Jurídicas, 2003.

12 Cfr. OC-18/03, 17 de septiembre de 2003, párr. 101; Norín Catrimán y otros (dirigentes, miembros y activista del Pueblo Indígena Mapuche), 29 de mayo de 2014, párr. 197, y Duque, 26 de febrero de 2016, párr. 91.

13 Cfr. OC-4/84, 19 de enero de 1984, párr. 55, y Flor Freire, 31 de agosto de 2016, párr. 109.

14 Cfr. García Ramírez, Sergio, Derechos humanos de los menores de edad: perspectiva de la jurisdicción interamericana, México, UNAM, Instituto de Investigaciones Jurídicas, 2010, p. 56; García Ramírez, Sergio y Martínez Breña, Laura, Presos y prisiones: el sistema penitenciario desde la perspectiva de los derechos humanos, México, Porrúa-UNAM, Coordinación de Humanidades-Programa Universitario de Derechos Humanos, 2014, pp. 8 y 9, y mi voto razonado al caso Ximenes Lopes, Fondo, Reparaciones y Costas, párr. 2. En sentido similar, Owen Fiss señala que debe entenderse la cláusula de igualdad a partir de la integración del concepto "grupo desaventajado" — group disadvantaging - que se refiere a un grupo social "que tiene una existencia distinta de la de sus miembros, que tiene una identidad propia". Fiss, Owen, "Grupos y la cláusula de igual protección”, en Gargarella, Roberto (comp.), Derecho y grupos desaventajados, Barcelona, Gedisa, pp. 138 y 139.

15 En este punto cobran presencia los factores de igualación en el ámbito procesal —igualdad por compensación_- invocados por Eduardo J. Couture en Estudios de derecho procesal civil, 2a. ed., Buenos Aires, Depalma, 1978, t. I, pp. 275 y 276, y las tutelas específicas, a las que se refiere Roberto Berizonce en Las tutelas procesales diferenciadas, Buenos Aires, Rubinzal-Culzoni, 2009. Evidentemente, nos hallamos en el cauce del dere- 
En este artículo, necesariamente breve dadas las reglas de publicación que debo atender, me propongo mirar hacia los datos sobresalientes de la jurisprudencia de la Corte IDH en torno a esta materia. Considero que la jurisprudencia del tribunal de San José tiene una de sus manifestaciones más destacadas precisamente en el ámbito que ahora nos interesa, y se inscribe en lo que podemos llamar, válidamente, la jurisprudencia "transformadora" de la Corte Interamericana.

La realidad de nuestra América - la América Latina, "espacio judicial" de la Corte $-{ }^{17}$ suscita esa atención especial hacia los integrantes de grupos reconocidos como vulnerables, algunos de los cuales no tienen la misma presencia en Europa, por ejemplo, y tampoco en áreas de la región sobre las que no se despliega la jurisprudencia del tribunal en vertiente contenciosa. En los siguientes apartados formularé una sucinta introducción a los diversos capítulos atendidos por la Corte en su desempeño jurisdiccional.

\section{MUJERES}

Las mujeres constituyen la porción más numerosa de la población. ${ }^{18}$ Sin embargo, han padecido un persistente y acentuado maltrato, que las constituye, paradójicamente, en "sector vulnerable". ${ }^{19}$ En el plano mundial figura un

cho social de orientación proteccionista. Cfr. García Ramírez, "El derecho social”, Revista de la Facultad de Derecho, México, t. XV, núm. 59, julio-septiembre de 1965, pp. 633 y ss.

16 En esa línea, la Corte IDH ha señalado que "toda persona que se encuentre en una situación de vulnerabilidad es titular de una protección especial, en razón de los deberes especiales cuyo cumplimiento por parte del Estado es necesario para satisfacer las obligaciones generales de respeto y garantía de los derechos humanos", y por ello resulta "imperativa la adopción de medidas positivas, determinables en función de las particulares necesidades de protección del sujeto de derecho, ya sea por su condición personal o por la situación específica en que se encuentre". Furlán y familiares, 31 de agosto de 2012, párr. 134.

17 En diversos trabajos me he referido a este "espacio"; por ejemplo, García Ramírez, La Corte Interamericana..., cit., pp. 33 y ss.

18 En 2016, las mujeres constituían el 50.56\% de la población de América Latina y el Caribe, mientras que en México representaban el 50.21\%, disponible en: https://data. worldbank.org/indicator/SP.POP.TOTL.FE.ZS? locations $=Z J \&$ view $=$ chart .

19 Reglas de Brasilia sobre Acceso a la Justicia de las Personas..., cit., sección 2a., 8; Protocolo de Actuación Judicial para Casos de Violencia de Género..., cit., pp. 15 y 16, y el contenido general de CEDAW, Observación General No. 19 "La violencia contra la mujer", 1992. 
instrumento - ampliamente suscrito y adoptado por los Estados integrantes de la comunidad internacional - que pretende erradicar la discriminación que agravia a las mujeres. ${ }^{20}$

Por lo que toca al hemisferio americano, se ha pugnado de tiempo atrás por contar con estructuras internacionales que favorezcan el reconocimiento y el ejercicio de los derechos de las mujeres. En este sentido, destaca la Comisión Interamericana de Mujeres, ${ }^{21}$ primer órgano de su género en el mundo. En América se cuenta con una convención específica para combatir la violencia contra aquéllas, que es el instrumento interamericano que cuenta con el mayor número de Estados parte. ${ }^{22}$ Los convenios mencionados, mundial y regional, han permeado en la legislación interna de los países americanos, entre ellos México. ${ }^{23}$

El tema de la igualdad jurídica entre hombres y mujeres fue examinado por la Corte IDH a través de su competencia consultiva, ${ }^{24}$ que apoyó esa igualdad y generó el "piso" de la jurisprudencia interamericana sobre cuestiones de género. Después de un largo periodo de ejercicio jurisdiccional en el que no hubo demandas por violación de derechos de mujeres — en su condición de tales, no a título de víctimas genéricas de vulneraciones, situación que fue muy frecuente-, el tribunal interamericano sostuvo su competencia para

20189 Estados, entre ellos México, son parte de la Convención para la Eliminación de Todas las Formas de Discriminación contra la Mujer (CEDAW), 1979.

21 Conforme al artículo 2o. de su Estatuto, la Comisión Interamericana de Mujeres es un órgano intergubernamental que funciona como el principal foro de debate y formulación de políticas públicas sobre los derechos de las mujeres y la igualdad de género. Esta organización internacional fue establecida en 1928 por la Sexta Conferencia Internacional de Estados Americanos. http://www.oas.org/es/cim/nosotros.asp.

22 Convención Interamericana para Prevenir, Sancionar y Erradicar la Violencia contra la Mujer "Convención de Belém do Pará", 1994, que cuenta con 32 Estados parte.

23 Ley General para la Igualdad entre Hombres y Mujeres, 2006, México, y Ley General de Acceso de las Mujeres a una Vida Libre de Violencia, 2007, México. En la misma línea, se reformaron diversas disposiciones del Código Penal Federal para introducir el tipo penal de feminicidio, y varios artículos relativos a delitos contra derechos reproductivos, hostigamiento y abuso sexual, discriminación, estupro, violación y fraude familiar. $C f r$. "Decreto por el que se reforman y adicionan diversas disposiciones del Código Penal Federal, de la Ley General de Acceso de las Mujeres a una Vida Libre de Violencia, de la Ley Orgánica de la Administración Pública Federal y de la Ley Orgánica de la Procuraduría General de la República”. Sobre este tema, $c f r$. Álvarez González, Rosa María y Pérez Duarte y Noroña, Alicia Elena (coords.), Aplicación práctica de los modelos de prevención, atención y sanción de la violencia de género contra las mujeres. Protocolos de actuación, 4a. ed., México, Conacyt-UNAM, Instituto de Investigaciones Jurídicas, 2014.

24 Cfr. OC-4/84, 19 de enero de 1984, párrs. 64-67. 
aplicar directamente la Convención de Belém do Pará, con fundamento en consideraciones sustantivas y procesales que franquearon la posibilidad de llevar a cabo esa aplicación. ${ }^{25}$ Hay sentencias posteriores que reafirman la competencia de la Corte para conocer violaciones de aquel tratado. ${ }^{26}$

A partir del reconocimiento de su competencia para aplicar la Convención de Belém do Pará, la Corte ha conocido de distintos casos sobre violencia contra la mujer, ${ }^{27}$ entre ellos: asuntos concernientes a violencia sexual ${ }^{28}$ (incluida la violación sexual), ${ }^{29}$ uso de estereotipos de género y omisión de prevenir e investigar con la debida diligencia, ${ }^{30}$ falta de investigación y sanción en casos de violencia contra la mujer ${ }^{31}$ — con especial énfasis en la investigación y juzgamiento con perspectiva de género $-{ }^{32}$ y afectación a derechos sexuales y reproductivos. ${ }^{33}$

25 Cfr. Voto razonado del juez Sergio García Ramírez, en Penal Miguel Castro Castro, párrs. 3-32. En este caso, la Corte Interamericana declaró, por primera vez, que se había violado la Convención de Belém do Pará. Cfr. Penal Miguel Castro Castro, 25 de noviembre de 2006, puntos resolutivos 4 y 6 . Fue aquí que la Corte se declaró competente (competencia material) para conocer violaciones a dicha Convención.

26 Cfr. González y otras ("Campo algodonero"), 16 de noviembre de 2009, párrs. 35 y ss.; Veliz Franco, 19 de mayo de 2014, párrs. 36-38, y Velásquez Paíz, 19 de noviembre de 2015, párr. 19.

27 Cfr. García Ramírez, "Los derechos de las mujeres y la jurisdicción interamericana de los derechos humanos", en Los derechos humanos de la mujer, Curso de Derechos Humanos de Donostia-San Sebastián, Servicio Editorial de la Universidad del país Vasco, vol. VIII, 2007, pp. 9-39.

28 Cfr. Penal Miguel Castro Castro, 25 de noviembre de 2006, párr. 308, y J., 27 de noviembre de 2013, párr. 360.

29 Cfr. Penal Miguel Castro Castro, 25 de noviembre de 2006, párrs. 311 y 312; Fernández Ortega y otros, 30 de agosto de 2010, párrs. 116-132; Rosendo Cantú y otra, 31 de agosto de 2010, párrs. 106-122; Masacres de El Mozote y lugares aledaños, 25 de octubre de 2012, párrs. 163-167, y Espinoza Gónzalez, 20 de noviembre de 2014, parr. 194.

30 Cfr. González y otras ("Campo Algodonero”), 16 de noviembre de 2009, párrs. 293 y 400-402; Veliz Franco y otros, 19 de mayo de 2014, párrs. 185 y 225; Velásquez Paiz y otros, 19 de noviembre de 2015, párrs. 145, 146 y 200-203; Yarce y otras, párrs. 194-196, y Gutiérrez Hernández y otros, 24 de agosto de 2017, párrs. 149, 184, 185.

31 Cfr. Masacre de las Dos Erres, 24 de noviembre de 2009, párrs. 136-141; Masacres de El Mozote y lugares aledaños, 25 de octubre de 2012, párrs. 255, y Gudiel Álvarez y otros ("Diario Militar"), 20 noviembre de 2012, párrs. 275, 276 y 281.

32 Cfr. González y otras ("Campo algodonero”), 16 de noviembre de 2009, párr. 455; Veliz Franco y otros, 19 de mayo de 2014, párr. 251, y Espinoza Gonzáles, 20 de noviembre de 2014, párr. 309.

33 Cfr. I.V., 30 de noviembre de 2016, párrs. 220, 235, 254 y 297. 


\section{NIÑAS, NIÑOS Y ADOLESCENTES ${ }^{34}$}

Se ha dicho que los niños son los sujetos vulnerables por antonomasia. ${ }^{35}$ En efecto, su condición suscita el ejercicio de una múltiple autoridad que puede culminar en el desconocimiento o la vulneración de sus derechos. Ocurre a través de acciones —o abstenciones - del Estado, de la sociedad y de la familia, tres sujetos a los que la Convención Americana atribuye deberes en relación con los niños, ${ }^{36}$ lo que no ocurre en otros supuestos.

La situación de los menores de edad fue abordada por la Convención de Naciones Unidas sobre los Derechos del Niño, a la que se estima como "parteaguas" en la definición de los derechos de este gran contingente ${ }^{37}$ y que cuenta con un número muy elevado de Estados parte. ${ }^{38}$ A partir de esta Convención se ha producido un notable conjunto de reformas en la legislación secundaria. ${ }^{39}$

No existe un instrumento interamericano de naturaleza convencional acerca de los niños. Se cuenta con un organismo regional de protección de la infancia, vinculado a la Organización de los Estados Americanos. ${ }^{40} \mathrm{La}$ Corte Interamericana se ha ocupado de esta cuestión por diversas vías: a

34 Individuos que aún no han cumplido dieciocho años. Cfr. artículo 1o. de la Convención sobre los Derechos del Niño, 1989, y Reglas de Brasilia..., cit., regla 5.

35 Cfr. Ferrajoli, Luigi, "Prefacio", en García Méndez, Emilio y Belloff, Mary (comps.), Infancia, ley y democracia en América Latina, Temis-Depalma, 1998, p. XI.

36 Cfr. OC-17/02, 28 de agosto de 2002, párrs. 62-70; Gelman, 24 de febrero de 2011, párr. 121, y Forneron e hija, 27 de abril de 2012, párr. 45. Del mismo modo, artículo 16 (derecho de la niñez) del Protocolo adicional a la Convención Americana sobre Derechos Humanos "Protocolo de San Salvador", 1988, y artículos 3o. y 4o. de la Convención sobre los Derechos del Niño, 1989. Igualmente, cfr. García Ramírez, Derechos humanos de los menores de edad..., cit., pp. 37 y 38.

37 Cfr. García Ramírez, Derechos humanos de los menores de edad..., cit., p. 32.

38 El tratado cuenta con 196 Estados parte.

39 Cfr. Ley General de Prestación de Servicios para la Atención, Cuidado y Desarrollo Integral Infantil, México, 2011; Ley General de los Derechos de Niñas, Niños y Adolescentes, México, 2014, y Ley de los Derechos de Niñas, Niños y Adolescentes de la Ciudad de México, México, 2015.

40 El Instituto Interamericano del Niño, la Niña y Adolescentes es un organismo de la Organización de los Estados Americanos (OEA) que apoya a los Estados en el desarrollo, diseño e implementación de políticas públicas desde la perspectiva de los derechos de las niñas, niños y adolescentes. Cfr. http://iin.oea.org/. 
través de opiniones consultivas ${ }^{41} \mathrm{y}$ de sentencias en casos contenciosos. ${ }^{42}$ En este último acervo destaca, por su carácter promotor de la defensa de los niños, con el más amplio alcance, la decisión que recayó al caso Niños de la Calle. ${ }^{43}$ En esta resolución, la Corte afirmó el deber estatal de generar condiciones de vida dignas para el desarrollo de los niños - aspecto positivo, se ha dicho, del derecho a la protección de la vida reconocido en el artículo 4o. de la $\mathrm{CADH}-{ }^{44}$

Es bien conocido el debate entre las corrientes denominadas "tutelar" y "garantista" en relación con el enjuiciamiento y el resguardo de los niños, particularmente los que se hallan en conflicto con la ley penal, a los que alguna vez se denominó "menores infractores". ${ }^{45}$ En la atención de estos asuntos y otros planteados en el mismo ámbito, la Corte Interamericana ha sostenido principios que informan su jurisprudencia sobre la materia: exaltación del interés superior del niño, ${ }^{46}$ consideración de éste como titular de derechos — no sólo sujeto de protección—, ${ }^{47}$ participación del niño en la definición de sus derechos, ${ }^{48}$ desarrollo integral, ${ }^{49}$ etcétera. Desde luego, la jurisprudencia interamericana se ha orientado en la línea que informa el principio de especificidad, esto es, el reconocimiento de las particularidades del niño, que justifican medidas especiales de pro-

$41 C f r . O C-17 / 02$, "Condición jurídica y derechos humanos del niño", 28 de agosto de 2002, y $O C-21 / 14$, "Derechos y garantías de niñas y niños en el contexto de la migración y/o en necesidad de protección internacional", 19 de agosto de 2014.

42 Cfr. Beloff, Mary, Los derechos del niño en el sistema interamericano, Buenos Aires, Del Puerto, 2009, pp. 193 y ss.

43 Cfr. "Niños de la Calle" (Villagrán Morales y otros). Fondo, 19 de noviembre de 1999, párrs. 187-198.

44 Cfr. ibidem, párrs. 191 y 197.

45 Cfr. Voto concurrente razonado del juez Sergio García Ramírez a la $O C-17 / 02$, párrs. 13 y ss. Asimismo, cfr. Ortega Soriano, Ricardo Alberto, Los derechos de las niñas y los niños en el derecho internacional, con especial atención al sistema interamericano de protección de los derechos humanos, México, CNDH, 2015, pp. 22-25.

46 Cfr. OC-17/02, 28 de agosto de 2002, párrs. 56 y ss.; Bulacio, 18 de septiembre de 2003, párr. 134, y Furlan y familiares, 31 de agosto de 2012, párr. 126.

47 Cfr. OC-17/02, 28 de agosto de 2002, párr. 41 y opinión 1.

48 Cfr. Atala Riffo y niñas, 24 de febrero de 2012, párrs. 196 y ss.; Furlan y familiares, 31 de agosto de 2012, párr. 230, y Familia Pacheco Tineo, 25 de noviembre de 2013, párr. 223.

49 Cfr. Atala Riffo y niñas, 24 de febrero de 2012, párrs. 108 y 196, y $O C-17 / 02,28$ de agosto de 2002, párrs. 41, 46-70, 80-92 y ss. 
tección, como se desprende del artículo 19 de la Convención Americana y del Protocolo de San Salvador. ${ }^{50}$

La jurisprudencia del tribunal ha resaltado la situación de vulnerabilidad en la que se encuentran los niños y adolescentes, ${ }^{51}$ que se incrementa en algunas situaciones ${ }^{52}$ - por ejemplo en los conflictos armado ${ }^{53}$ y cuando existen condiciones de riesgo- $-{ }^{54} \mathrm{El}$ órgano jurisdiccional interamericano se ha pronunciado sobre las garantías de los menores de edad en procesos judiciales que definan o afecten sus derechos, ${ }^{55}$ la situación de los menores privados de la libertad, ${ }^{56}$ las garantías de los niños migrantes ${ }^{57}$

50 Cfr. "Niños de la Calle" (Villagrán Morales y otros). Fondo, 19 de noviembre de 1999, párr. 196.

51 Cfr. Hermanos Gómez Paquiyauri, 8 de julio de 2004, párr. 76; Comunidades Afrodescendientes Desplazadas de la Cuenca de Río Cacarica (Operación Génesis), 20 de noviembre de 2013, párrs. 329 y 330; Veliz Franco y otros, 19 de mayo de 2014, párr. 134, y $O C-21 / 14,19$ de agosto de 2014, párr. 71.

52 La Corte IDH se pronunció sobre la interseccionalidad de la discriminación; el tribunal señaló la particularidad de la discriminación sufrida por la víctima debido a la confluencia de diversos factores de vulnerabilidad. En ese caso, Talia Gabriela González era niña, mujer, tenía discapacidad, vivía con VIH y se hallaba en una posición económica desfavorable. Cfr. Gónzales Lluy y otros, 1o. de septiembre de 2015, párr. 285.

53 Cfr. OC-17/02, 28 de agosto de 2002, párr. 82; "Masacre de Mapiripán”, Fondo, Reparaciones y Costas, 15 de septiembre de 2005, párr. 156.

54 Cfr. "Niños de la Calle" (Villagrán Morales y otros), Fondo, 19 de noviembre de 1999, párr. 197; Servellón García y otros, 21 de septiembre de 2006, párrs. 116 y 117; Ximenes Lópes, Fondo, Reparaciones y Costas, 4 de julio de 2006, párr. 104, y OC-17/02, párr. 82.

55 Cfr. OC-17/02, 28 de agosto de 2002, párrs. 92-98; Atala Riffo y niñas, 24 de febrero de 2012, párrs. 196 y ss., y Mendoza y otros, 14 de mayo de 2013, párrs. 144 y ss.

56 Cfr. Bulacio, 18 de septiembre de 2003, párrs. 126 y 134-136, e "Instituto de Reeducación del Menor", 2 de septiembre de 2004, párrs. 160-163 y 230.

57 Cfr. OC-21/14, "Derechos y garantías de niñas y niños en el contexto de la migración y/o en necesidad de protección internacional", 19 de agosto de 2014. Asimismo, Liwski, Norberto I., Migraciones de niñas, niños y adolescentes bajo el enfoque de derechos, Montevideo, Instituto Interamericano del Niño, la Niña y Adolescentes, disponible en: http://www.derechosinfancia.org.mx/Documentos/Migraciones_liwski. $p d f$, y Ortega Velásquez, Elisa, Estándares para niñas, niños y adolescentes migrantes y obligaciones del Estado frente a ellos en el sistema interamericano de derechos humanos, México, CNDH, 2017. Sobre México, cfr. Consejo Ciudadano del Instituto Nacional de Migración, Personas en detención migratoria en México, México, 2017, pp. 32 y ss.; Instituto Interamericano de Derechos Humanos, Prácticas relevantes de protección a los derechos de los niños, niñas y adolescentes migrantes en el triángulo norte y México, San José, IIDH, 2016, pp. 21-65, y Lorenzen Martiny, Matthew James, Migración de niñas, niños y adolescentes: antecedentes y análisis de información de la 
y refugiados, ${ }^{58}$ e igualmente se ha ocupado de las medidas de protección debidas a los menores de edad con discapacidad. ${ }^{59}$

\section{INDÍGENAS ${ }^{60}$}

La composición demográfica, histórica y actual de una buena parte del Continente Americano lleva a observar con particular atención el estado que guardan los pueblos originarios, la población indígena, y también la afrodescendiente, que llegó a América, para su desventura, en la era del esclavismo. ${ }^{61}$ Ambas constituyen un relevante sector de la población en varios Estados del Continente y el Caribe. ${ }^{62}$

red de módulos y albergues de los sistemas DIF, 2007-2016, México, Consejo Nacional de Población, 2016, pp. 73-95.

58 Cfr. Familia Pacheco Tineo, 25 de noviembre de 2013, párrs. 219-229.

59 Cfr. Furlan y familiares, 31 de agosto de 2012, párrs. 128-139. En el mismo sentido, Comité de los Derechos del Niño, Observación General No. 9, "Los derechos de los niños con discapacidad", 27 de febrero de 2007.

60 El concepto de "pueblos indígenas" no posee un significado uniforme en el ámbito internacional; su definición se elabora a partir del contexto y circunstancias de cada Estado. Así, en América Latina el concepto es flexible y subjetivo, y atiende a criterios como la lengua materna, los lazos familiares y la autoidentificación, aunque en los últimos años se han incorparado elementos territoriales. Cfr. Stavenhagen, Rodolfo, The emergence of indigenous people, Heildelberg-NuevaYork-Londres-Dordrecht, Springer-El Colegio de México, 2013, pp. 46-48.

La Comisión Interamericana de Derechos Humanos (CIDH) ha establecido que si bien no existe un concepto único en el derecho internacional, hay elementos que guían hacia una aproximación: a) la descendencia de las poblaciones que habitaban antes de la conquista o el establecimiento de fronteras, y que, además, conserven sus instituciones, económicas, sociales y políticas o parte de ellas; b) conciencia de su identidad indígena, es decir, la autoidentificación; c) conexión territorial, y d) experiencias de discriminación o exclusión. Cfr. CIDH, Derechos de los pueblos indígenas y tribales sobre sus tierras ancestrales y recursos naturales. Normas y jurisprudencia del sistema interamericano de derechos humanos, OEA/Ser.L/V/II, Doc. 56/09, 30 de diciembre de 2009, pp. 10 y 11.

En México, el artículo 2o. de la Constitución define a los "pueblos indígenas" como "aquellos que descienden de poblaciones que habitaban en el territorio actual del país al iniciarse la colonización y que conservan sus propias instituciones sociales, económicas, culturales y políticas, o parte de ellas".

61 Cfr. Iturralde Nieto, Gabriela y Velásquez Gutiérrez, María Elisa, Afrodescendientes en México. Una historia de silencio y discriminación, México, Consejo Nacional para Prevenir la Discriminación-Instituto Nacional de Antropología e Historia, 2013, pp. 44-47.

62 De acuerdo con la Comisión Económica para América Latina y el Caribe (CEPAL), en 2010 existían 44,791,456 personas indígenas en el continente americano. Cfr. 
En torno a los derechos de los indígenas, se han producido movimientos constitucionales y legislativos en diversos países, ${ }^{63}$ como ha ocurrido en México; ${ }^{64}$ asimismo, existe una normativa internacional que paulatinamente gana terreno ${ }^{65}$ (con especial énfasis en el Convenio 169 de la OIT), ${ }^{66}$ lo cual

CEPAL, Los pueblos indígenas en América Latina: avances en el último decenio y retos pendientes para la garantía de sus derechos, Santiago, Naciones Unidas, p. 43.

En lo que respecta a México, según el Instituto Nacional de Estadística y Geografía (INEGI), el porcentaje de población que se autoadscribía como población indígena - reconocimiento que realiza la población con base en sus concepciones- ascendía a $21.5 \%$ del total de la población $(29,882,688)$ en 2015 , disponible en: http://www.beta.inegi.org. mx/app/indicadores/\#divFV6207019014.

63 En las últimas décadas se han adoptado leyes y reformas en los ordenamientos jurídicos de: Argentina (1994), Estado Plurinacional de Bolivia (1994, 2004 y 2009), Brasil (1988/2005), Colombia (1991 y 2003), Costa Rica (1999), Ecuador (1996, 1998 y 2008), El Salvador (1983/2000), Guatemala (1985/1998), Honduras (1982/2005), México (1992, 1994/1995 y 2001), Nicaragua (1987, 1995 y 2005), Panamá (1972, 1983 y 1994), Perú (1993 y 2005), Paraguay (1992), y Venezuela (República Bolivariana de) (1999). Cfr. CEPAL, Los pueblos indígenas en América ..., cit., pp. 17 y 18.

64 En 2001 se reformó el artículo 2o. de la Constitución Política de los Estados Unidos Mexicanos, que incorporó diversos derechos de pueblos y comunidades indígenas. Asimismo, existen tanto leyes federales como locales. Las federales son: Ley General de los Derechos Lingüísticos de los Pueblos Indígenas y la Ley de la Comisión Nacional para el Desarrollo de los Pueblos Indígenas. Las de entidades federativas — veintiséisregulan los derechos, cultura y organización de los pueblos y comunidades indígenas, disponibles en: http://www.cndh.org.mx/Indigenas_Marco_Normativo. La Suprema Corte ha adoptado un protocolo para la actuación en casos que involucren derechos de personas, comunidades o pueblos indígenas. Cfr. SCJN, Protocolo de actuación para quienes imparten justicia en casos que involucren derechos de personas, comunidades y pueblos indigenas..., cit., pp. 45 y ss.

También, cfr. Cuevas Gayosso, José Luis, "Las decisiones políticas fundamentales en materia indígena: el Estado pluricultural en México", en varios autores, Pluralismo jurídico y pueblos indígenas. XIII Jornadas Lascasianas Internacionales, México, UNAM, Instituto de Investigaciones Jurídicas, 2005, pp. 96-105, y Toro Huerta, Mauricio Iván del y Juárez Santiago, Rodrigo, La perspectiva intercultural en la protección y garantía de los derechos humanos (una aproximación desde el análisis de las controversias electorales en comunidades indigenas), México, CNDH, 2015, Colección sobre la Protección Constitucional de los Derechos Humanos.

65 Convenio 107 de la OIT sobre Poblaciones Indígenas y Tribales, 1957; Convenio 169 de la OIT sobre Pueblos Indígenas y Tribales en Países Independientes, 1989; Declaración Americana sobre los Derechos de los Pueblos Indígenas, 2016; Reglas de Brasilia sobre Acceso a la Justicia..., cit., 2008, y Protocolo de Actuación Judicial para casos de Violencia de Género..., cit., 2014.

66 El Convenio 169 adoptó normas que informaron la evolución del derecho internacional desde la adopción del Convenio 107. En el cuerpo de aquel Convenio se incorporó el reconocimiento del control que asumen sobre sus instituciones y formas 
no implica, en modo alguno, ni remotamente, que los indígenas vivan y progresen en condiciones de igualdad — no quiero decir asimilación- con otros sectores de la población.

Como anteriormente he manifestado,${ }^{67}$ las violaciones a derechos humanos de los indígenas ${ }^{68}$ pueden distribuirse en varios extremos, que conforman una severa tipología: eliminación física, que constituye etnocidio; ${ }^{69}$ privación de territorios y otros bienes, ${ }^{70}$ ataques a la cultura, ${ }^{71}$ y obstáculos a la participación en la toma de decisiones, que atañe a los derechos políticos, entre otros. ${ }^{72}$ Veamos enseguida un sucinto panorama sobre el desarrollo

de vida, y el fortalecimiento de su cultura e identidad. Lo anterior respondió a una reivindicación de la cultura de los pueblos indígenas. Cfr. Ordoñez Cifuentes, José Emilio Rolando, "Antecedentes doctrinarios del derecho internacional público moderno: integracionismo e indigenismo de participación”, en Ordoñez Cifuentes, José Emilio Rolando (coord.), XVII Jornadas Lascacianas Internacionales, contacto y cooperación a través de fronteras, Convenio 169 de la OIT, pueblos originarios y afroamericanos, México, UNAM, Instituto de Investigaciones Jurídicas, 2009, pp. 29-32.

67 Cfr. García Ramírez, "Los indígenas en la jurisprudencia de la Corte Interamericana de Derechos Humanos", en Ordóñez Cifuentes, José Emilio Rolando (coord.), $X V$ Jornadas Lascasianas Internacionales, México, UNAM, 2007, pp. 31-44.

68 Sobre este tema, cfr. Quintana Osuna, Karla I. y Góngora Maas, Juan Jesús, Los derechos de los pueblos indigenas y tribales en los sistemas de derechos humanos, México, CNDH-UNAM, Instituto de Investigaciones Jurídicas, 2017, y Stavenhagen, Rodolfo, Los derechos humanos de los pueblos indígenas, México, CNDH, 2000.

69 Cfr. Masacre Plan de Sánchez. Reparaciones, 19 de noviembre 2004, párrs. 49 y ss.; Chitay Nech y otros, 25 de mayo de 2010, párrs. 64, 93 y 103; Masacres de Río Negro, 4 de septiembre de 2012, párrs. 58 y 127, y Miembros de la Aldea Chichupac y comunidades vecinas del Municipio de Rabinal, 30 de noviembre de 2016, párrs. 76, 77 y 160.

70 Cfr. Comunidad Mayagna (Sumo) Awas Tingni. Fondo, Reparaciones y Costas, 31 de agosto de 2001, párrs. 143 y ss.; Comunidad Indigena Sawhoyamaxa, 29 de marzo de 2006, párrs. 117 y ss., y Pueblo Indígena Kichwa de Sarayaku, 27 de junio de 2012, párrs. 85 y ss. He analizado el régimen de propiedad que corresponde a la comunidad indígena, diferente de la propiedad privada o el dominio pleno: una propiedad comunal como fundamento y garantía de los derechos individuales de los integrantes de aquélla. Cfr. Voto razonado del juez Sergio García Ramírez, en Comunidad Mayagna (Sumo) Awas Tingni, 31 de agosto de 2001, párrs. 12-17.

71 Cfr. Masacre Plan de Sánchez, Reparaciones, 19 de noviembre de 2004, párrs. 85 y ss.; Comunidad Indígena Yakye Axa, 17 de junio de 2005, párrs. 146, 147 y 154; López Álvarez, 1o. de febrero de 2006, párrs. 169-174; Comunidad Indígena Xákmok Kásek, 24 de agosto de 2010, párrs. 174-182; Pueblo Indígena Kichwa de Sarayaku, 27 de junio de 2012, párr. 213; Chitay Nech y otros, 25 de mayo de 2010, párrs. 146 y 147, y Masacres de Río Negro, 4 de septiembre de 2012, párr. 160.

72 Cfr. Yatama, 23 de junio de 2005, párrs. 191-226; Chitay Nech y otros, 25 de mayo de 2010, párrs. 113-118, y Norín Catrimán y otros (Dirigentes, miembros y activista del Pueblo Indígena Mapuche), 29 de mayo de 2014, párrs. 383-386. 
de la jurisprudencia relacionada con derechos y libertades de indígenas americanos y afrodescendientes.

La jurisprudencia interamericana ha sostenido que los pueblos y comunidades indígenas y tribales ${ }^{73}$ son reconocidos en el ámbito internacional como sujetos colectivos de derecho. ${ }^{74}$ Por consiguiente, la vulneración de sus derechos afecta tanto a la comunidad como a sus miembros.

En ese mismo sentido, la Corte IDH se ha pronunciado en diversas ocasiones sobre la propiedad comunal de los pueblos indígenas, destacando la especial conexión de éstos con sus territorios ancestrales. ${ }^{75}$ El tribunal ha establecido que los Estados tienen la obligación de delimitar, demarcar y titular los territorios, ${ }^{76}$ así como consultar a las comunidades cuando se afecten sus intereses, ${ }^{77}$ y remover obstáculos que impidan el uso y goce de los bienes ${ }^{78}$ y sus recursos naturales. ${ }^{79}$

Igualmente, la Corte IDH se ha pronunciado sobre las afectaciones de los pueblos en casos de desplazamiento forzado, ${ }^{80}$ porque, como mencioné

73 La Corte IDH ha conocido casos sobre comunidades tribales, que "no son pueblos indígenas de la región que habitan, pero comparten características similares con los pueblos indígenas". Pueblo Saramaka, Fondo, 28 de noviembre de 2007, párr. 79.

74 Cfr. Pueblo indigena Kichwa de Sarayaku, Fondo y Reparaciones, 27 de junio de 2012, párr. 231, y $O C-22 / 16,26$ de febrero de 2016, párrs. 72 y ss.

75 Cfr. Mayagna (Sumo) Awas Tigni, Fondo, Reparaciones y Costas, 31 de agosto de 2001, párr. 149; Pueblo indigena Kichwa de Sarayaku, Fondo y Reparaciones, 27 de junio de 2012, párr. 155; Pueblos Kaliña y Lokono, 25 de noviembre de 2015, párr. 129, y Pueblo Indígena Xucuru y sus miembros, 5 de febrero de 2018, párr. 115. Igualmente, cfr. Toro Huerta, Mauricio Iván del, "El derecho de propiedad colectiva de los miembros de comunidades y pueblos indígenas en la jurisprudencia de la Corte Interamericana de Derechos Humanos", Anuario Mexicano de Derecho Internacional, 2010, vol. X, enerodiciembre de 2010, pp. 49-91.

76 Cfr. Mayagna (Sumo) Awas Tigni, Fondo, Reparaciones y Costas, 31 de agosto de 2001, párr. 164; Comunidad Garífuna Triunfo de la Cruz y sus miembros, 8 de octubre de 2015, párr. 105, y Pueblo Indígena Xucuru y sus miembros, 5 de febrero de 2018, párr. 117.

77 Cfr. Pueblo Saramaka, 28 de noviembre de 2007, párr. 143, y Pueblo indígena Kichwa de Sarayaku, Fondo y Reparaciones, 27 de junio de 2012, párr. 155.

78 Cfr. Mayagna (Sumo) Awas Tigni, Fondo, Reparaciones y Costas, 31 de agosto de 2001, párr. 153, y Comunidad Garifuna de Punta Piedra y sus miembros, 8 de octubre de 2015, párr. 181.

79 Cfr. Pueblo indigena Kichwa de Sarayaku, Fondo y Reparaciones, 27 de junio de 2012, párr. 146, y Pueblos Kaliña y Lokono, 25 de noviembre de 2015, párr. 132.

80 Cfr. Chitay Nech y otros, 25 de mayo de 2010, párr. 147, y Masacres de Río Negro, 4 de septiembre de 2012, párr. 177. 
arriba, existe una relación especial entre las comunidades y sus tierras o territorios, lo cual podría generar afectaciones en su tejido étnico y cultural. ${ }^{81}$

\section{PERSONAS CON DISCAPACIDAD ${ }^{82}$}

La tutela uniforme de los derechos de las personas tropieza con obstáculos derivados de las limitaciones físicas — con repercusión social— de muchas personas que presentan alguna forma de discapacidad. ${ }^{83}$ De ahí la atención especial que es preciso adoptar en estos supuestos, a los que se refieren tanto la regulación mundial ${ }^{84}$ como la interamericana, que se anticipó a aquélla. ${ }^{85}$ Con la misma orientación se ha pronunciado la Suprema Corte de Justicia de México a través de un protocolo específico ${ }^{86}$ y en igual sentido se orientan las Reglas de Brasilia ${ }^{87}$ y el Protocolo de Santiago. ${ }^{88}$

La Corte Interamericana cuenta con resoluciones importantes a propósito de los derechos humanos de personas con discapacidad. En aquéllas

81 Cfr. Masacres de Río Negro, 4 de septiembre de 2012, párr. 177.

82 "Las personas con discapacidad incluyen a aquellas que tengan deficiencias físicas, mentales, intelectuales o sensoriales a largo plazo que, al interactuar con diversas barreras, puedan impedir su participación plena y efectiva en la sociedad, en igualdad de condiciones con las demás". Artículo 1o. de la Convención sobre los Derechos de las Personas con Discapacidad, 2006.

83 Cfr. Gonzáles Lluy y otros, 1o. de septiembre de 2015, párr. 237, y Chinchilla Sandoval, 29 de febrero de 2016, párr. 207. En la misma línea, cfr. Gallegos Flores, Joaquín, "Los derechos humanos de las personas con discapacidad. Análisis teórico y normativo del sistema universal a la luz de los principios de libertad, igualdad y solidaridad", en varios autores, Discapacidad y derecho, SCJN, 2016, pp. 44 y 45; Palacios, Agustina, El modelo social de discapacidad: orígenes, caracterización y plasmación en la Convención Internacional sobre los Derechos de las Personas con Discapacidad, Ediciones Cinca-Comité Español de Representantes de Personas con Discapacidad, 2018, pp. 103 y ss., y SCJN, Protocolo de actuación para quienes imparten justicia..., cit., pp. 7 y 8.

84 Convención sobre los Derechos de las Personas con Discapacidad, 2006.

85 Convención Interamericana para la Eliminación de Todas las Formas de Discriminación contra las Personas con Discapacidad, 1999.

86 SCJN, Protocolo de actuación para quienes imparten justicia..., cit., pp. 7 y ss.

87 "Se procurará establecer las condiciones necesarias para garantizar la accesibilidad de las personas con discapacidad al sistema de justicia, incluyendo aquellas medidas conducentes a utilizar todos los servicios judiciales requeridos y disponer de todos los recursos que garanticen su seguridad, movilidad, comodidad, comprensión, privacidad y comunicación”. Reglas de Brasilia sobre Acceso a la Justicia..., cit., sección 2.3.

88 Protocolo Iberoamericano de Actuación Judicial para Mejorar el Acceso a la Justicia..., cit., p. 231. 
se afirma el deber del Estado de proveer vigilancia y cuidado sobre el trato a estas personas, incluso cuando quedan a cargo de sujetos o instituciones de derecho privado, por subrogación o encomienda estatal ${ }^{89}$ este es un deber de custodia que puede generar responsabilidades por omisión en la diligencia debida. ${ }^{90}$

El tribunal ha adoptado el modelo social de discapacidad, ${ }^{91}$ que implica la interrelación de las deficiencias con las barreras sociales existentes. Por ello, la Corte ha establecido, por ejemplo, que vivir con VIH/Sida ${ }^{92}$ o padecer infertilidad biológica ${ }^{93}$ pueden ser consideradas discapacidades, en la medida en que impiden el pleno goce de derechos.

En lo que respecta al acceso a la justicia, el orden internacional de los derechos humanos de personas que presentan alguna forma de discapacidad - especialmente, pero no exclusivamente, alteraciones psíquicas - prevé la adopción de "medidas especiales" o "ajustes razonables" 94 en los procedimientos judiciales, a fin de asegurar el buen acceso a la justicia y la emisión de decisiones justas. ${ }^{95}$ En esta dirección existe normativa mexicana inserta en el Código Nacional de Procedimientos Penales. ${ }^{96}$

En el tema de la ejecución de penas, la Corte Interamericana se ha pronunciado en el mismo sentido, es decir, por la adopción de ajustes razonables en los casos que involucren a personas con discapacidad, para eliminar los

89 Cfr. Ximenes Lopes, 4 de julio de 2006, párrs. 89 y 90.

90 Cfr. ibidem, párrs. 133 y ss.

91 "[E]l modelo social de discapacidad entiende la discapacidad como el resultado de la interacción entre las características funcionales de una persona y las barreras en su entorno". Furlan y familiares, párr. 133; Gonzalés LLuy y otros, 1o. de septiembre de 2015, párr. 237, y Chinchilla Sandoval, 29 de febrero de 2016, párr. 207.

92 Cfr. Gonzalés Lluy y otros, 1o. de septiembre de 2015, párrs. 236-238.

93 Cfr. Artavia Murillo y otros ("Fecundación in vitro"), 28 de noviembre de 2012 , párr. 293.

94 Las "medidas especiales" o "ajustes razonables" son las "modificaciones y adaptaciones necesarias y adecuadas que no impongan una carga desproporcionada o indebida, cuando se requieran en un caso particular, para garantizar a las personas con discapacidad el goce o ejercicio, en igualdad de condiciones con las demás, de todos los derechos humanos y libertades fundamentales". Artículo 2o. de la Convención sobre los Derechos de la Personas con Discapacidad (2006). Con las particularidades del caso, cfr. Chinchilla Sandoval, 29 de febrero de 2016, párrs. 208 y ss.

95 Cfr. Furlan y familiares, 31 de agosto de 2012, párr. 196. Además, artículo 14.2 de la Convención sobre los Derechos de la Personas con Discapacidad, 2006.

96 Artículos 10, 109, f.XII y 414 del Código Nacional de Procedimientos Penales, México, 2014. 
obstáculos que les impiden ejercer sus derechos en condiciones de igualdad. ${ }^{97}$ La normativa mexicana, tanto federal como local, adopta la misma perspectiva sobre el tratamiento de personas con discapacidad privadas de la libertad. ${ }^{98}$

\section{MigRANTES ${ }^{99}$}

Los procesos migratorios - internos e internacionales - datan de mucho tiempo y revisten múltiples características. En la actualidad, la migración internacional ofrece rasgos peculiares tanto en América como en otras regiones del mundo. Son bien conocidos los problemas que estos procesos plantean en Europa: así, entre los Estados europeos y diversas comunidades asiáticas, africanas o americanas. ${ }^{100}$ La Organización Internacional para las Migraciones (OIM) ha destacado la existencia de un gran número de migrantes internacionales, ${ }^{101}$ la localización de las corrientes migratorias y

97 Cfr. Chinchilla Sandoval, 29 de febrero de 2016, párrs. 208 y ss.

98 La Ley Nacional de Ejecución Penal dispone en su artículo 4o. los principios rectores del ordenamiento, entre los cuales se encuentra la igualdad, que comprende la aplicación de ajustes razonables en casos de personas con discapacidad. En el mismo sentido, la Ley de Ejecución de Sanciones Penales y Reinserción para el Distrito Federal establece, en su artículo 9o., el uso de ajustes razonables para que las personas con discapacidad compurguen la pena conforme a los lineamientos del derecho internacional de los derechos humanos.

99 En el ámbito internacional no existe un concepto uniforme sobre el término "migrante", aunque es usualmente utilizado para referirse a quienes se encuentran fuera de su país o territorio de origen de manera voluntaria. Cfr. CIDH, Movilidad humana. Estándares interamericanos, OEA/Ser.L/V/II, Doc. 46/15, 31 de diciembre de 2015, p. 124 , y Organización Internacional para las Migraciones (OIM), Glosario sobre migración, OIM, 2006, p. 41. En cambio, en el ámbito nacional, la Ley de Migración (artículo 3o.) define al migrante como: "individuo que sale, transita o llega al territorio de un Estado distinto al de su residencia por cualquier tipo de motivación".

100 Cfr. ONU, Informe del Secretario General, Migración internacional y desarrollo, 2 de agosto de 2010, párrs. 11 y ss. Asimismo, cfr. Bustamante, Jorge A., Migración internacional y derechos humanos, México, UNAM, 2002; "Los derechos del extraño: migrantes y desplazados", prólogo de Sergio García Ramírez a Comisión Nacional de los Derechos Humanos, Migrantes. Voces, rostros y sueños compartidos, México, CNDH, 2016, pp. 15-33; Morales Gamboa, Abelardo, "Dinámica actual y contexto de las migraciones en América Latina", Revista IIDH, San José, 9-11 de agosto de 2004, pp. 1-60, y Council of European Union, General Secretariat of the Council, Council conclusions on migration, October 12th 2015, p. 2.

101 De acuerdo con la OIM, en 2015 el número de migrantes ascendió a 243,700,236, lo que representó el 3.3\% de la población mundial. Cfr. OIM, World Migration Report 
el hecho de que ese conjunto constituiría, de hallarse concentrado, uno de los países más poblados del planeta. ${ }^{102}$

Existen múltiples cuestiones asociadas al fenómeno migratorio: el trabajo de quienes cruzan las fronteras nacionales de manera formal y de quienes lo hacen sin contar con los documentos que acrediten su estancia legal en el país de tránsito o destino; ${ }^{103}$ la situación en que se hallan los familiares de los migrantes en general, y especialmente de los trabajadores migrantes indocumentados; los derechos de aquéllos y éstos; los problemas que surgen con motivo de procedimientos administrativos o judiciales en relación con migrantes; y el gran flujo de recursos económicos que éstos hacen llegar a sus familiares en los países de origen - las denominadas "remesas", que son cuantiosas y contribuyen significativamente a la economía familiar-. ${ }^{104}$

El derecho internacional cuenta con instrumentos a propósito de la situación jurídica de los migrantes. ${ }^{105}$ En el orden jurídico mexicano se han

2018, OIM, 2017, p. 15. En México, según el INEGI, la población migrante de 5 años y más ascendía a 3,292,310 en 2010.

102 Cfr. OIM, World Migration..., cit., p. 19. Sobre las tendencias globales de migración, cfr. OIM, Global Flows, disponible en: http://www.iom.int/world-migration. Acerca de los movimientos migratorios de refugiados y solicitantes de asilo, véase, United Nations High Commissioner for Refugees (UNHCR), Global Trends 2010, UNHCR, 2011, disponible en: http://www.unhcr.org/4dfa11499.html. Sobre la situación de la migración en América Latina, cfr. CIDH, Movilidad humana..., cit., pp. 17-34.

103 Cfr. OIM, World Migration Report..., cit., pp. 13 y ss.

104 Las remesas alcanzaron una cifra global de "536,989 mil millones de dólares" en 2016; en México, la cifra fue de "28,691 mil millones". Cfr. https://data.worldbank.org/ indicator/BX.TRF.PWKR.CD.DT? end $=2016 \&$ start $=1970 \&$ view $=$ chart . Sobre este tema, $c f r$. Orozco, Manuel, "Remesas hacia Latinoamérica y el Caribe: cuestiones y perspectivas acerca del desarrollo", Revista IIDH, San José, 9-11 de agosto de 2004, pp. 61-134.

105 La CIDH señala que en el ámbito internacional existen dos grandes regímenes normativos que regulan la situación jurídica de los migrantes: por una lado, los regímenes específicos sobre la protección de apátridas, refugiados, víctimas de trata y desplazados internos, y por otro, el derecho internacional de los derechos humanos. Cfr. CIDH, Movilidad humana..., cit., párrs. 82 y ss.

Dentro del primer régimen se encuentran, entre otros instrumentos: Convención sobre el Estatuto de los Refugiados, 1951; Convención sobre el Estatuto de los Apátridas, 1954; Protocolo sobre el Estatuto de los Refugiados, 1967; Convenio sobre las Migraciones en Condiciones Abusivas y la Promoción de la Igualdad de Oportunidades y de Trato de los Trabajadores Migrantes, 1975; Declaración de Cartagena sobre Refugiados, 1984; Convención Internacional sobre la Protección de los Derechos de Todos los Trabajadores Migratorios y sus Familiares, 1990; Protocolo contra el Tráfico Ilícito de Migrantes por Tierra, Mar y Aire, que complementa la Convención de las Naciones Unidas contra la Delincuencia Organizada Transnacional, 1999; Protocolo para Prevenir, Reprimir y San- 
producido importantes novedades en este ámbito; ${ }^{106}$ así, se suprimió la criminalización de migrantes indocumentados a través de tipos penales específicos. ${ }^{107}$ No obstante el relevante aparato normativo internacional y nacional, la situación de los migrantes sigue siendo grave y en muchas ocasiones crítica; padecen múltiples obstáculos para el desarrollo regular de su vida y sufren innumerables violaciones a sus derechos humanos. ${ }^{108}$

cionar la Trata de Personas, especialmente Mujeres y Niños, que complementa la Convención de las Naciones Unidas contra la Delincuencia Organizada Transnacional, 2000, y Convención de la Unión Africana para la Protección y Asistencia de los Desplazados Internos en África (Convención de Kampala), 2009.

En el segundo, entre otros instrumentos: Declaración Americana de los Derechos y Deberes del Hombre (artículos VIII y XXVII), 1948; Declaración Universal de Derechos Humanos (artículos 9o., 13 y 14), 1948; Protocolo núm. 4 del Convenio Europeo de Derechos Humanos (artículos 2o., 3o. y 4o.), 1963; Pacto Internacional de Derechos Civiles y Políticos (artículos 12 y 13), 1966; Convención Americana sobre Derechos Humanos (artículo 22), 1969, y Carta Africana sobre los Derechos Humanos y de los Pueblos (artículo 12), 1981.

Sobre los derechos humanos de las personas migrantes en el derecho internacional, cfr. Calleros Alarcón, Juan Carlos (coord.), La protección de los derechos humanos de las personas migrantes: una guía para las y los servidores públicos, México, Centro de Estudios Migratorios-Unidad de Política Migratoria, 2012, pp. 57 y ss.

106 En el ámbito nacional existen leyes generales que regulan la movilidad — Ley de Migración, 2011, y Ley sobre Refugiados, Protección Complementaria y Asilo Político, 2011- y también se han generado leyes en el ámbito local para la protección de los migrantes, por ejemplo, la Ley de Interculturalidad, Atención a Migrantes y Movilidad Humana en el Distrito Federal, 2011.

Además, $c f r$. varios autores, La protección de los derechos humanos de las personas migrantes..., cit., pp. 81 y ss.

107 En 2011, se derogaron diversos tipos penales en materia migratoria: artículo 156 del Código Penal Federal, y artículos 138 y 139 de la Ley General de Población.

108 Cfr. CIDH, Movilidad humana ..., cit., párrs. 8-10, 16 y ss. La Corte Interamericana ha señalado que "(g)eneralmente los migrantes se encuentran en una situación de vulnerabilidad como sujetos de derechos humanos, en una condición individual de ausencia o diferencia de poder con respecto a los no-migrantes (nacionales o residentes). Esta condición de vulnerabilidad tiene una dimensión ideológica y se presenta en un contexto histórico que es distinto para cada Estado, y es mantenida por situaciones de jure (desigualdades entre nacionales y extranjeros en las leyes) y de facto (desigualdades estructurales). Esta situación conduce al establecimiento de diferencias en el acceso de unos y otros a los recursos públicos administrados por el Estado”. OC-18/03, párr. 112.

De la misma forma, la Asamblea General de las Naciones Unidas ha resaltado la situación de vulnerabilidad en la que se encuentran los migrantes debido a las dificultades culturales y económicas que afrontan, así como a la violencia y discriminación de las que son víctimas. Cfr. Asamblea General de las Naciones Unidas, Resolución A/RES/54/166 sobre "Protección de los migrantes", 24 de febrero de 2000, p. 2. 
La jurisprudencia interamericana ha tenido un interesante desempeño en esta materia. ${ }^{109}$ Se ha ocupado de un amplio conjunto de cuestiones: derechos de extranjeros sujetos a procedimientos penales, que deben contar con protección consular - ésta figura en el marco del debido proceso, como garantía de defensa adecuada - ${ }^{: 110}$ garantías indispensables en procedimientos migratorios; ${ }^{111}$ derechos humanos de los trabajadores migrantes indocumentados, que no pueden ser vulnerados por la normativa interna de los países de residencia o por las políticas adoptadas por éstos en diversos rubros; ${ }^{112}$ derecho de buscar y recibir asilo ${ }^{113} \mathrm{u}$ obtener la condición de refugiado; ${ }^{114}$ principio de no devolución; ${ }^{115}$ prohibición de expulsiones colectivas determinadas por motivos raciales ${ }^{116}$ rechazo a la apatridia, ${ }^{117}$ y derechos de quienes se han visto desplazados de los lugares de su origen o residencia por diversos factores: económicos, políticos, delictivos, etcétera. ${ }^{118}$ Existe una relevante jurisprudencia acerca de desplazamientos internacionales o domésticos, ${ }^{119}$

109 Cfr. Morales Sánchez, Julieta, Derechos de los migrantes en el sistema interamericano de derechos humanos, México, CNDH, 2015, pp. 34-62.

110 Cfr. OC-16/99, 1o. de octubre de 1999, párr. 122; Bueno Alves, 11 de mayo de 2007, párr. 116; Chaparro Álvarez y Lapo Íñiguez, 21 de noviembre de 2007, párr. 164, y Vélez Loor, 23 de noviembre de 2010, párrs. 157-159. También, cfr. Prólogo de Héctor Fix Zamudio, en Opinión Consultiva OC-16 de la Corte Interamericana de Derechos Humanos, México, Secretaría de Relaciones Exteriores, 2001.

111 Cfr. OC-18/03, 17 de septiembre de 2003, párrs. 122 y ss.; Vélez Loor, 23 de noviembre de 2010, párr. 143; Nadege Dorzema, 24 de octubre de 2012, párr. 159, y OC21/14, 19 de agosto de 2014, párrs. 108 y ss.

112 Cfr. OC-18/03, 17 de septiembre de 2003, párrs.149 y 153.

113 Cfr. Familia Pacheco Tineo, 25 de noviembre de 2013, párrs. 137 y ss., y OC21/14, 19 de agosto de 2014, párrs. 73-82.

114 Cfr. Familia Pacheco Tineo, 25 de noviembre de 2013, párrs. 144-150.

115 Cfr. ibidem, párrs. 151-153; Wong Ho Wing, 30 de junio de 2015, párrs. 127-129, y $O C-21 / 14,19$ de agosto de 2014, párrs. 207 y ss.

116 Cfr. Nadege Dorzema y otros, 24 de octubre de 2012, párrs. 176-178 y 228-238, y Personas haitianas y dominicanas expulsadas, párrs. 381-384 y 398-404.

117 Cfr. Niñas Yean y Bosico, párrs. 142, 155 y 167; Personas haitianas y dominicanas expulsadas, 28 de agosto de 2014, párrs. 256-264, y OC-21/14, 19 de agosto de 2014, párrs. 94-96.

118 Cfr. Comunidad Moiwana, 15 de junio de 2005, párr. 111; Masacres de Mapiripan, Fondo, Reparaciones y Costas, 15 de septiembre de 2005, párrs. 171 y ss.; Chitay Nech y otros, 25 de mayo de 2010, párr. 149, y Miembros de la Aldea Chichupac y comunidades vecinas del Municipio de Rabinal, 30 de noviembre de 2016, párrs. 175 y 176.

119 La Corte IDH ha considerado que son desplazados internos "las personas o grupos de personas que se han visto forzadas u obligadas a escapar o huir de su hogar o de su 
como secuela o efecto de contiendas internas. ${ }^{120}$ Asimismo, el tribunal interamericano ha dictado pertinentes medidas provisionales para proteger a los migrantes — adultos o niños - de violaciones muy graves, inminentes, difícilmente reparables por otros medios. ${ }^{121}$

\section{PERSONAS EN SITUACIÓN DE POBREZA ${ }^{122}$}

\section{Las condiciones de pobreza o incluso de indigencia o miseria que pade- cen amplios sectores de la sociedad favorecen la vulneración de derechos}

lugar de residencia habitual, en particular como resultado o para evitar los efectos de un conflicto armado, de situaciones de violencia generalizada, de violaciones de los derechos humanos..., y que no han cruzado una frontera estatal internacionalmente reconocida". Chitay Nech y otros, 25 de mayo de 2010, párr. 140.

120 Cfr. Masacres de Mapiripan, Fondo, Reparaciones y Costas, 15 de septiembre de 2005, párr. 172; Masacres de Ituango, 1o. de julio de 2006, párr. 208; Masacres de El Mozote y lugares aledaños, 25 de octubre de 2012, párr. 193, y Comunidades Afrodescendientes desplazadas de la Cuenca del Río Cacarica (Operación Génesis), 20 de noviembre de 2013, párrs. 283 y ss.

121 Cfr. Asunto haitianos y dominicanos de origen haitiano en la República Dominicana respecto República Dominicana. Medidas Provisionales. Resolución de la Corte Interamericana de Derechos Humanos del 18 de agosto de 2000, puntos resolutivos 3-6, y Asunto Wong Ho Wing. Medidas Provisionales respecto del Perú. Resolución de la Corte del 28 de mayo de 2010, punto resolutivo 1 .

122 No existe un concepto único de "pobreza" o "pobreza extrema". El Comité de Derechos Económicos, Sociales y Culturales de las Naciones Unidas ha señalado que "puede definirse como una condición humana que se caracteriza por la privación continua o crónica de los recursos, la capacidad, las opciones, la seguridad y el poder necesarios para disfrutar de un nivel de vida adecuado y de otros derechos civiles, culturales, económicos, políticos y sociales". Cfr. ONU, Consejo Económico y Social, Comité de Derechos Económicos, Sociales y Culturales, Cuestiones sustantivas que se plantean en la aplicación del Pacto Internacional de Derechos Económicos, Sociales y Culturales: la pobreza y el Pacto Internacional de Derechos Económicos, Sociales y Culturales, E/C.12/2001/10, 10 de mayo de 2001, párr. 8. Por otro lado, la CIDH ha determinado que "la pobreza constituye un problema que se traduce en obstáculos para el goce y ejercicio de los derechos humanos en condiciones de igualdad real por parte de las personas, grupos y colectividades que viven en dicha situación. La situación de pobreza trae consigo una exposición acentuada a violaciones de derechos humanos; vulnerabilidad incrementada por las restricciones derivadas de la situación socioeconómica de las personas". CIDH, Pobreza y derechos humanos, OEA/Ser.L/V/II.164, Doc. 147, 7 de septiembre de 2017, párr. 92. En México, el Coneval adopta un criterio multidimensional de pobreza; considera que "(u)na persona se encuentra en situación de pobreza multidimensional cuando no tiene garantizado el ejercicio de al menos uno de sus derechos para el desarrollo social, 
humanos, además de la violación que aquellas condiciones entrañan, por sí mismas, en tanto impiden o reducen la calidad de vida o desarrollo de quienes las padecen. Son diversas las caracterizaciones de la pobreza, que no pretendo examinar en este artículo. En todo caso, procede señalar que la pobreza se identifica como factor de vulnerabilidad - que obstruye el acceso a la justicia - tanto en las Reglas de Brasilia ${ }^{123}$ como en el Protocolo de Santiago de Chile. ${ }^{124}$

En la jurisprudencia de la Corte Interamericana hay resoluciones atentas al problema de la pobreza. ${ }^{125}$ Así, se releva del agotamiento de recursos internos a quien, merced a su situación de indigencia, no puede valerse de aquéllos y necesita acceder a la vía internacional. ${ }^{126}$ Igualmente, la Corte se ha pronunciado sobre el derecho de los pobres a contar con defensa en procedimientos judiciales — no sólo penales - y el consiguiente deber estatal de proveer defensa pública en esas situaciones. ${ }^{127}$

y si sus ingresos son insuficientes para adquirir los bienes y servicios que requiere para satisfacer sus necesidades". Consejo Nacional de Evaluación de la Política de Desarrollo Social, Metodología para la medición multidimensional de la pobreza en México, 2a. ed., Coneval, 2014, p. 37.

Igualmente, $c f r$. Parra Vera, Óscar, "Derechos humanos y pobreza en el sistema interamericano. El rol de análisis estructural a partir de informes y siete escenarios estratégicos basados en la responsabilidad internacional", Revista IIDH, vol. 56, p. 274, y Cáceres, Luis Rene et al., "Pobreza y derechos humanos: hacia la definición de parámetros conceptuales desde la doctrina y acciones del sistema interamericano", en varios autores, ¿Quién responde por los derechos humanos de las poblaciones más pobres en América Latina y El Caribe? Democracia vs. desigualdad (2007-2011), San José, Instituto Interamericano de Derechos Humanos, pp. 13-155.

123 Reglas de Brasilia..., cit., sección 2a., punto 7.

124 El protocolo no hace referencia específica a las personas en situación económica desfavorable; sin embargo, el documento refiere al principio de no discriminación en casos que involucren a niños, niñas y adolescentes, los cuales suelen ser estigmatizados por su situación de pobreza; igualmente, se refiere a la adopción de medidas especiales en aquellos casos de menores de edad en situación de riesgo. Cfr. Protocolo iberoamericano de actuación judicial..., cit., pp. 33 y 41.

125 Sobre este punto, $c f r$. Parra Vera, Óscar, "Derechos humanos y pobreza en el sistema interamericano...", cit., pp. 288-301, y Ferrer Mac Gregor, Eduardo, La justiciabilidad de los derechos económicos, sociales, culturales y ambientales en el sistema interamericano de derechos humanos, México, UNAM, Instituto de Investigaciones Jurídicas, 2017, pp. 206-214.

126 Cfr. OC-11/90, 10 de agosto de 1990, párr. 31.

127 Cfr. Vélez Loor, 23 de noviembre de 2010, párr. 146; OC-11/90, 10 de agosto de 1990, párr. 28, y $O C-18 / 03,17$ de septiembre de 2003, párr. 126. 
El tribunal ha manifestado, asimismo, que la pobreza es un reflejo de la exclusión de grupos sociales, y ha apuntado que la condición económica también es causa de violaciones ${ }^{128}$ o agravante de éstas; ${ }^{129}$ en especial, destacó la interrelación entre la pobreza y la exclusión social con respecto a la discapacidad. ${ }^{130}$

Aunado a lo anterior, el tribunal se ha pronunciado acerca de una de las facetas de la pobreza: la falta de acceso a servicios básicos. La Corte ha considerado que la falta de acceso a alimentación, agua, salud ${ }^{131}$ y educación, ${ }^{132}$ así como la precariedad de los servicios en centros de reclusión, ${ }^{133}$ constituyen violaciones relacionadas con la situación económica de las personas.

En 2016, el tribunal se pronunció por primera vez sobre la discriminación estructural histórica que sufrieron 85 trabajadores en razón de una "categoría sospechosa" establecida en el artículo 1.1 de la Convención Americana - "posición económica"-, condenando al Estado por no considerar ese factor de vulnerabilidad de los trabajadores. ${ }^{134}$ En este caso, la situación en que se hallaban los trabajadores constituía una forma de esclavitud. ${ }^{135}$

\section{PRIVADOS DE LA LIBERTAD}

La privación de libertad es una situación que trae consigo la especial vulnerabilidad de quienes se hallan sujetos a esta restricción o limitación de un derecho fundamental. ${ }^{136}$ Nos referimos a la privación de la libertad en

\footnotetext{
128 Cfr. Servellón García y otros, 21 de septiembre de 2006, párr. 117.

129 Cfr. Uzcátegui y otros, 3 de septiembre de 2012, párr. 204.

130 Cfr. Ximenes Lopes, 4 de julio de 2006, párr. 104.
}

131 La Corte ha resaltado que la extrema pobreza es un factor de morbilidad y mortalidad materna. Cfr. Comunidad indígena Xákmok Kásek, 24 de agosto de 2010, párr. 233.

132 Cfr. Comunidad indígena Yakye Axa, 17 de junio de 2005, párrs. 161-176, y Comunidad indígena Xákmok Kásek, 24 de agosto de 2010, párrs. 268-274.

133 Cfr. "Instituto de Reeducación del Menor", 2 de septiembre de 2004, párrs. 159-163.

134 Cfr. Trabajadores de la Hacienda Brasil Verde, 20 de octubre de 2016, párrs. 334341. Sobre la incorporación de la situación económica como categoría sospechosa, $c f r$. Voto del juez Eduardo Ferrer Mac-Gregor Poisot en Trabajadores de la Hacienda Brasil Verde, 20 de octubre de 2016, párrs. 4 y ss.

135 Cfr. Trabajadores de la Hacienda Brasil Verde, 20 de octubre de 2016, párrs. 304306,343 , y punto resolutivo 3 .

136 Se presenta una especial situación de vulnerabilidad debido al fuerte control o dominio que ejerce la autoridad sobre quienes se hallan en estas condiciones; además, la 
los términos y por los supuestos recogidos tanto en el Convenio europeo sobre derechos fundamentales ${ }^{137}$ como en los principios enunciados por la Comisión Interamericana de Derechos Humanos, ${ }^{138}$ que abarcan cualquier forma de privación de la libertad por disposición del poder público, no sólo los supuestos vinculados a un procedimiento penal o a una sentencia de condena. Esta situación adquiere especial gravedad en las hipótesis de internamiento en las denominadas "instituciones totales". 139

En la jurisprudencia interamericana destaca la atención a la muy deplorable situación que guardan los sujetos privados de libertad - procesados, sentenciados, internos en establecimientos de educación o salud-. La Corte ha señalado las pésimas condiciones que prevalecen en muchos establecimientos de custodia y ejecución de penas, ${ }^{140}$ que a menudo son escenarios de violaciones graves y masivas de los derechos de sus habitantes. ${ }^{141} \mathrm{La}$ Corte ha dictado resoluciones notables en casos que pudieran caracterizarse como "paradigmáticos", ${ }^{142}$ tomando en cuenta la extrema violencia que han padecido los internos, tanto adultos como menores de edad.

privación de la libertad conlleva la restricción de otros derechos. Cfr. "Instituto de Reeducación del Menor", 2 de septiembre de 2004, párrs. 152 y 154.

137 Artículo 5.1 del Convenio Europeo para la Protección de los Derechos Humanos y de las Libertades Fundamentales (1950).

138 Principios y Buenas Prácticas sobre la Protección de las Personas Privadas de Libertad en las Américas, adoptados por la Comisión Interamericana de Derechos Humanos durante el 131o. periodo ordinario de sesiones, celebrado del 3 al 14 de marzo de 2008.

139 Las "instituciones totales", como la prisión, entrañan que la vida cotidiana de quienes se encuentran recluidos en ellas se halle "sujeta a una minuciosa orientación, con múltiples modalidades y restricciones sobre todas las actividades del recluso, mucho más que la vida del individuo libre. Se trata de una experiencia específica, desconocida para la gran mayoría de la población"; García Ramírez y Martínez Breña, Presos y prisiones..., cit., p. 97. Asimismo, cfr. mis votos razonados en Bulacio, 18 de septiembre de 2003, párr. 23, y Ximenes Lopes, 4 de julio de 2006, párr. 22.

140 Cfr. Loayza Tamayo, Fondo, 17 de septiembre de 1997, párr. 58; "Instituto de Reeducación del Menor", 2 de septiembre de 2004, párrs. 159-170; Chinchilla Sandoval, 29 de febrero de 2016, párr. 169 y ss., y Asunto de las Penitenciarías de Mendoza respecto Argentina. Medidas Provisionales. Resolución de la Corte Interamericana de Derechos Humanos del 22 de noviembre de 2004, considerando 10.

141 Cfr. "Instituto de Reeducación del Menor", 2 de septiembre de 2004, párrs. 147 y ss.; Penal Miguel Castro Castro, 25 de noviembre de 2006, párrs. 267 y ss., y Pacheco Teruel y otros, 27 de abril de 2012, párrs. 63 y ss.

142 Cfr. Neira Alegría, Fondo, 19 de enero de 1995, párrs. 60 y ss.; Durand y Ugarte, Fondo, 16 de agosto de 2000, párrs. 64 y ss.; "Instituto de Reeducación del Menor", 2 de septiembre de 2004, párrs. 147 y ss.; Montero Aranguren y otros (Reten de Catia), 5 
En esta materia destacan los señalamientos sobre las condiciones de vida digna que es debido asegurar a los reclusos; ${ }^{143}$ la prohibición de medidas que inciden sobre derechos humanos más allá de la afectación inherente a la pena privativa de libertad en sí misma, ${ }^{144}$ el deber especial de garantía que incumbe al Estado con respecto a quienes se hallan sujetos a restricciones en el ejercicio de su libertad, ${ }^{145}$ etcétera.

\section{Periodistas ${ }^{146}$}

\section{Hasta aquí me he referido a individuos o grupos reconocidos como vul- nerables en documentos internacionales y protocolos que he citado en los}

de julio de 2006, párrs. 63 y ss.; Penal Miguel Castro Castro, 25 de noviembre de 2006, párrs. 233 y ss., y Pacheco Teruel y otros, 27 de abril de 2012, párrs. 63 y ss.

143 Cfr. "Instituto de Reeducación del Menor", 2 de septiembre de 2004, párr. 159; Lori Berenson Mejía, 25 de noviembre de 2004, párr. 102, y García Asto y Ramírez Rojas, 25 de noviembre de 2005, párr. 221. En el mismo sentido, la Corte IDH señaló en su Informe ante la Comisión de Asuntos Jurídicos y Políticos de la OEA que "(e)n diversos casos se ha observado que existe una verdadera crisis en el sistema de reclusorios para adultos y menores de edad. Esta crisis se traduce en extremada violencia y genera riesgos constantemente señalados. La Corte ha dictado resoluciones sobre medidas provisionales en las que se formulan diversas observaciones a este respecto y se urge a las autoridades a revisar a fondo el sistema de reclusorios. Parece indispensable que la Organización y los Estados dediquen especial atención al examen de este problema y provean soluciones inmediatas y progresivas, según las circunstancias". Consejo Permanente de la OEA, Comisión de Asuntos Jurídicos y Políticos, Síntesis del Informe Anual de la Corte Interamericana de Derechos Humanos correspondiente al ejercicio de 2005, 16 de marzo de 2006, OEA/Ser.G, CP/CAJP-2344/06, pp. 18 y 19.

144 Cfr. Penal Miguel Castro Castro, 25 de noviembre de 2006, párr. 314.

145 Cfr. Bulacio, 18 de septiembre de 2003, párr. 126; Tibi, 7 de septiembre de 2004, párr. 129, y Vélez Loor, 23 de noviembre de 2010, párr. 216.

146 Si bien el concepto de "periodista" dista de ser uniforme en nuestro continente, los órganos del sistema interamericano han señalado que "el periodista profesional es simplemente quien ejerce su libertad de expresión en forma continua, estable y remunerada". CIDH, Relatoría especial para la libertad de expresión, Marco jurídico interamericano sobre el derecho a la libertad de expresión, OEA/Ser.L/V/II, CIDH/RELE/INF. 2/09, 30 de diciembre de 2009, párr. 168. Igualmente, $c f r$. Corte IDH, OC-5/85, 13 de noviembre de 1985, párr. 74, y Vélez Restrepo, 3 de septiembre de 2012, párr. 140.

En México, la Ley para la Protección de Personas Defensoras de Derechos Humanos y Periodistas señala, en su artículo 2o., que se entiende por periodista a "(1)as personas físicas, así como medios de comunicación y difusión públicos, comunitarios, privados, independientes, universitarios, experimentales o de cualquier otra índole cuyo trabajo consiste en recabar, generar, procesar, editar, comentar, opinar, difundir, publicar o pro- 
diversos apartados de este artículo. Sin embargo, la relación que he mencionado no agota el tema de los vulnerables desde la perspectiva de los derechos humanos y al amparo de la jurisprudencia tutelar de la Corte Interamericana. Las condiciones de la vida social y política - en constante cambio - y las novedades de la cultura, que pone a la vista espacios que se hallaban ocultos o distraídos, han incrementado el universo de quienes hoy día resultan vulnerables $-\mathrm{y}$ han sido efectivamente vulnerados, en el curso de muchos años o en el presente- y de los que se ha ocupado, con especial acento, el tribunal de San José.

Es así que conviene agregar a la relación formulada hasta ahora otros actores del amplio campo de los derechos humanos cuya presencia y protección jurisdiccional — además de la provista por la Comisión Interamericanafigura en opiniones consultivas, sentencias o medidas provisionales de la mayor importancia. Concurren a integrar la jurisprudencia "transformadora" del tribunal de San José.

Por el orden de aparición en la escena de la tutela jurisdiccional, parece pertinente mencionar en primer término a los periodistas. De la actividad de éstos se ha ocupado la Corte en diversas oportunidades, ${ }^{147}$ reconociendo la importancia y trascendencia de la función del periodista en la sociedad democrática. ${ }^{148}$ La jurisprudencia carga el acento sobre la protección especial que merecen los periodistas, ${ }^{149}$ frecuentemente asediados o victimados por acciones autoritarias que vulneraron distintos derechos: protección de la vida, integridad personal, expresión, entre otros. ${ }^{150}$ Han sido frecuentes las sentencias y las medidas provisionales en este ámbito.

veer información, a través de cualquier medio de difusión y comunicación que puede ser impreso, radioeléctrico, digital o imagen".

147 Cfr. OC-5/85, 13 de noviembre de 1985; Herrera Ulloa, 2 de julio de 2004, párrs. 105 y ss.; Kimel, 2 de mayo de 2008, párrs. 51 y ss.; Fontevecchia y D’amico, 29 de noviembre de 2011, párrs. 42 y ss.; Vélez Restrepo, 3 de septiembre de 2012, párrs. 123 y ss., y Memoli, 22 de agosto de 2013, párrs. 117 y ss.

148 Cfr. Ivcher Bronstein, 6 de febrero de 2001, párrs. 149 y 150; Herrera Ulloa, 2 de julio de 2004, párrs. 117 y 118, y CIDH, Marco jurídico interamericano sobre el derecho a la libertad de expresión, OEA/Ser.L/V/II, CIDH/RELE/INF. 2/09, 30 de diciembre de 2009, párrs. 165-169.

149 Cfr. Ivcher Bronstein, 6 de febrero de 2001, párr. 150; Herrera Ulloa, 2 de julio de 2004, párr. 119, y Vélez Restrepo y familiares, 3 de septiembre de 2012, párr. 194.

150 Cfr. Carpio Nicolle y otros, 22 de noviembre 2004, párrs. 76 y 82; Vélez Restrepo y familiares, 3 de septiembre de 2012, párrs. 142-148; Perozo y otros, 28 de enero de 2009, párrs. 141-143, y Granier y otros (Radio caracas televisión), 22 de junio de 2015, párrs. 197 y 198. 
Es preciso reconocer que el libre ejercicio del periodismo se ha visto sujeto a presiones y agresiones inaceptables, que proliferaron - y permanecenen diversos países. Esto vulnera tanto los derechos de los profesionales del periodismo y sus allegados como el "ámbito general" de los derechos humanos. Diversos señalamientos de organismos internacionales han puesto en evidencia la violación de derechos humanos de periodistas en México, que ha recibido enérgicas recomendaciones de las relatorías sobre libertad de expresión de Naciones Unidas y de la Comisión Interamericana. ${ }^{151} \mathrm{Si}$ ha habido violación frecuente de derechos de periodistas, determinada por el desempeño profesional de éstos, se justifica que se les considere como una categoría de individuos vulnerables y que la Corte IDH resuelva medidas especiales de protección a cargo del Estado. ${ }^{152}$

\section{DEFENSORES DE DERECHOS HUMANOS ${ }^{153}$}

La creciente y comprometida actividad de instituciones de la sociedad civil y de individuos que actúan en la promoción y defensa de los derechos

151 Cfr. ONU, Informe del Relator Especial sobre la promoción y protección del derecho a la libertad de opinión y de expresión sobre su misión a México, A/HRC/17/27/ Add.3, 19 de mayo de 2011, párrs. 90-96; ONU-CIDH, Relatores especiales sobre libertad de expresión, Observaciones preliminares, visita conjunta a México, 27 de noviembre al 4 de diciembre 2017, párrs. 8 y ss.; CIDH, Relatoría especial para la libertad de expresión, Informe especial sobre la libertad de expresión en México 2010, OEA/Ser.L/V/ II, 7 de marzo de 2011, párrs. 291 y ss., y CIDH, Relatoría especial para la libertad de expresión, Zonas sileciadas: regiones de alta peligrosidad para ejercer la libertad de expresión, OEA/Ser.L/V/II, CIDH/RELE/INF.16/17, 15 de marzo de 2017, párrs. 36 y ss.

152 Cfr. Asunto diarios "El Nacional" y "Así es la noticia", Medidas Provisionales, 6 de julio de 2004, párr. 11 y Resolutivo 1, y Asunto de la Emisora de Televisión "Globovisión”, Medidas Provisionales, 4 de septiembre de 2004, párrs. 10-14.

153 La Corte IDH señala que la calidad de defensor de derechos humanos "radica en la labor que se realiza, con independencia de que la persona que lo haga sea un particular o un funcionario público", y ha resaltado las actividades de vigilancia, denuncia y educación en materia de derechos humanos que éstos realizan; Valle Jaramillo y otros, 27 de noviembre de 2008, párr. 88; Luna López, 10 de octubre de 2013, párr. 122, y Defensor de derechos humanos y otros, 28 de agosto de 2014, párr. 129. La CIDH ha señalado que debe entenderse a "toda persona que de cualquier forma promueva o procure la realización de los derechos humanos y las libertades fundamentales reconocidos a nivel nacional o internacional"; CIDH, Segundo informe sobre la situación de las defensoras y defensores de derechos humanos en las Américas, OEA/Ser.L./V/II/, Doc.66, 31 de diciembre de 2011, p. 4. 
humanos ha suscitado reacciones violatorias por autoridades públicas y por particulares cuya conducta genera responsabilidad internacional del Estado. En la especie, se trata de hechos que afectan de diversa forma y con distinta intensidad — que puede ser extrema - a los "defensores de derechos humanos". ${ }^{154}$

También aquí se ha pronunciado con fuerza la jurisprudencia interamericana, disponiendo medidas de protección a cargo de los Estados y emitiendo condenas contra éstos. ${ }^{155}$ Es importante destacar ciertas áreas en las que han ocurrido violaciones de derechos humanos; tal es el caso de algunos "defensores del medio ambiente", ${ }^{156}$ que por este motivo adquieren presencia en el universo de los sujetos vulnerables.

\section{LGBTI ${ }^{157}$}

En años recientes se ha modificado radicalmente — modificación que corre en un proceso de resistencia y reivindicación diligente - la situación de

En México, la Ley para la Protección de Personas Defensoras de Derechos Humanos y Periodistas - en su artículo 2o.- señala que las personas defensoras de derechos humanos son aquellas "personas físicas que actúen individualmente o como integrantes de un grupo, organización o movimiento social, así como personas morales, grupos, organizaciones o movimientos sociales cuya finalidad sea la promoción o defensa de los derechos humanos".

154 Cfr. CIDH, Informe sobre la situación de las defensoras y defensores de derechos humanos en las Américas, OEA/Ser.L/V/II.124, Doc. 5 rev.1, 7 de marzo de 2006, párrs. 137 y ss., y CIDH, Segundo informe sobre la situación de defensoras y defensores de derechos humanos en las Américas, OEA/Ser.L/V/II, 31 de diciembre de 2011, párrs. 20 y ss.

155 Condenas: Kawas Fernández, 3 de abril de 2009; Luna López, 10 de octubre de 2013, y Defensor de derechos humanos, 28 de agosto de 2014.

Medidas provisionales: Asunto Digna Ochoa y Plácido y otros respecto a México. Medidas Provisionales. Resolución de la Corte Interamericana de Derechos Humanos del 28 de agosto de 2001; Asunto del Centro de Derechos Humanos de Miguel Agustín Pro Juárez y otros respecto a México. Medidas Provisionales. Resolución de la Corte Interamericana de Derechos Humanos del 20 de abril de 2004, y Caso Kawas Fernández. Medidas Provisionales. Resolución de la Corte Interamericana de Derechos Humanos de 5 de julio de 2011.

156 Cfr. Kawas Fernández, 3 de abril de 2009, párrs. 147-149, y Luna López, 10 de octubre de 2013, párrs. 121-123.

157 El acrónimo LGBTI (que en ocasiones se presenta como LGBTTTI) comprende varios conceptos: lésbico, gay, bisexual, trans e intersex). Se utiliza "para describir a los diversos grupos de personas que no se ajustan a las nociones convencionales o tradi- 
quienes tienen rasgos o preferencias sexuales o de género que difieren de los prevalecientes en la mayoría de la población, y que por ello se han sumado al contingente de los vulnerables y vulnerados. Se ha desplegado la reclamación de derechos y el activismo de quienes conforman los diversos sectores del conjunto reconocido bajo las siglas LGBTI. ${ }^{158}$

En este ámbito también se manifiesta una creciente jurisprudencia interamericana, que pone de manifiesto los "nuevos derechos" de los integrantes de uniones entre personas del mismo sexo, ${ }^{159}$ la libertad de elección y asunción de la propia identidad, ${ }^{160}$ el reconocimiento y la protección de familias integradas en forma diferente de la denominada tradicional, parejas homosexuales y las reales o supuestas tensiones entre el interés superior del niño ${ }^{161}$ y las implicaciones familiares, patrimoniales y de seguridad

cionales de los roles de género masculinos y femeninos". La terminología "no es fija y evoluciona rápidamente, y (además) existen otras diversas formulaciones que incluyen a personas Asexuales, Queers, Trasvestis, Transexuales, entre otras". OC-24/17, 24 de noviembre de 2017, párr. 32. Las caracterizaciones que mencionamos a continuación figuran en esa fuente, así como en CIDH, Relatoría de Derechos LGTBI. Conceptos básicos, disponible al 1o. de junio de 2018 en http://www.oas.org/es/cidh/multimedia/2015/vio lencia-lgbti/terminologia-lgbti.html. En dichas fuentes se informa: la expresión lesbiana se refiere a "mujeres que se sienten emocional, sexual y románticamente atraídas a otras mujeres". Bajo el término gay se alude a "hombre(s) que se sienten emocional, afectiva y sexualmente atraído(s) por otros hombres". La expresión bisexual se asocia a "personas que se sienten emocional, sexual y románticamente atraídas a hombres y mujeres". Por otro lado, trans es "un término sombrilla utilizado para describir las diferentes variantes de la identidad de género, cuyo común denominador es la no conformidad entre el sexo asignado al nacer de la persona y la identidad de género que ha sido tradicionalmente asignada a ést(a). Una persona transgénero o trans puede identificarse con los conceptos de hombre, mujer, hombre trans, mujer trans y persona no binaria, o bien con otros términos como hijra, tercer género, biespiritual, travesti, fa'afafine, queer, transpinoy, muxé, waria y meti". Finalmente, la intersexualidad se refiere a "todas aquellas situaciones en las que la anatomía sexual de la persona no se ajusta físicamente a los estándares culturalmente definidos para el cuerpo femenino o masculino".

158 Cfr. Principios de Yogyakarta, p. 6, y SCJN, Protocolo de actuación para quienes imparten justicia..., cit., pp. 7 y ss. Sobre la violencia contra las personas LGBTI, cfr. CIDH, Violencia contra..., cit., pp. 37 y ss.

159 Cfr. Duque, 26 de febrero de 2016, párrs. 104 y ss., y $O C-24 / 17,24$ de noviembre de 2017, párrs. 173 y ss. Igualmente, la Corte ha determinado incluir la orientación y la identidad de género como categorías sospechosas en el análisis del principio de no discriminación. Cfr. Atala Riffo y niñas, 24 de febrero de 2012, párr. 91; Duque, 26 de febrero de 2016, párr. 104, y Flor Freire, 31 de agosto de 2016, párr. 118.

160 Cfr. OC-24/17, 24 de noviembre de 2017, párrs. 85 y ss., y opinión 2.

161 Cfr. Atala Riffo y niñas, 24 de febrero de 2012, párrs. 107-111. 
social de quienes han optado por constituir uniones o establecer familias conforme a sus propias orientaciones sexuales o identidad de género. Estos pronunciamientos de la Corte IDH también forman parte de la extensa y renovadora jurisprudencia que atiende derechos de individuos o grupos vulnerables.

Fecha de recepción: 6 de junio de 2018.

Fecha de aceptación: 29 de enero de 2019. 